\title{
Preparation techniques alter the mineral and organic fractions of fish otoliths: insights using Raman micro-spectrometry
}

\author{
Aurélie Jolivet ${ }^{1,2,{ }^{*}}$, Ronan Fablet ${ }^{3,4}$, Jean-François Bardeau ${ }^{5}$, Hélène de Pontual ${ }^{1}$ \\ 1 Département des Sciences et Technologies Halieutiques, Ifremer, Z.I. Pointe du diable, CS 10070, 29280, \\ Plouzané, France \\ 2 Institut Universitaire Européen de la Mer, Laboratoire des Sciences de L'Environnement Marin (UMR 6539), \\ Université de Bretagne Occidentale, Technopôle Brest Iroise, Place Nicolas Copernic, 29280, Plouzané, France \\ ${ }^{3}$ UMR 3192 LabSTICC, Institut Telecom/Telecom Bretagne, Technopole Brest Iroise, CS83818, 29238, Brest \\ Cedex 03, France \\ ${ }^{4}$ Université Européenne de Bretagne, 5 Boulevard Laënnec, 35000, Rennes, France \\ ${ }^{5}$ Institut des Molécules et Matériaux du Mans (UMR CNRS 6283), LUNAM Université, Avenue Olivier Messiaen, \\ 72085, Le Mans Cedex 09, France \\ *: Corresponding author : Aurélie Jolivet, email address : Aurelie.Jolivet@univ-brest.fr
}

\begin{abstract}
:
The high spatial resolution analysis of the mineral and organic composition of otoliths using Raman micro-spectrometry involves rigorous protocols for sample preparation previously established for microchemistry and trace elements analyses. These protocols often include otolith embedding in chemically neutral resin (i.e., resins which do not contain, in detectable concentration, elements usually sought in the otoliths). Such embedding may however induce organic contamination. In this paper, Raman micro-spectrometry reveals the presence of organic contamination onto the surface obtained from the use of epoxy resin, specifically Araldite. This contamination level varies depending on otolith structures. Core and checks, known as structural discontinuities, exhibit the most important level of contaminations. Our results suggest that otolith embedding with resin affects the organic matrix of the otolith, probably through an infiltration of the resin in the crystalline structure. The interpretation of chemical otolith signatures, especially Raman otolith signatures, and stable isotope analyses should then be revised in light of these results. In this respect, we propose a method for the correction of Raman otolith signatures for contamination effects.
\end{abstract}

Keywords: Epoxy resin ; Otolith composition ; Microstructure ; Raman spectrometry 


\section{Introduction}

Otoliths are calcareous concretions in inner ear of fish, consisting of calcium carbonate, mainly in form of aragonite (90-99 \% of the total otolith mass) and an organic fraction [1]. Their accretional growth on a circadian rhythm is both physiologically controlled and influenced by environmental conditions. Otolith chemical signatures provide invaluable cues for marine ecology including individual life histories, population structure, larval dispersal and population connectivity $[2,3]$. Because they are metabolically inert (unlikely to be resorbed) and grow throughout the lifespan, otoliths are considered to be highly effective continuous natural markers of the pas environmental history of the fish [2]. As previously reported, the chemical otolith composition may reflect modification of both temperature and elemental composition of the ambient water but in practice, the quantitative analysis of the otolith composition remain a complicated task in part due to technical difficulties and experimental methodologies. The effect of possible chemical contamination has been a cause of concerns [4-7] and several protocols based on contamination-free instruments and environments have been proposed for the different preparation steps, i.e. extraction, cleaning, conservation, handling, resin embedding and sectioning of the otoliths [8].

Very recently, new insights on the mineral and organic composition of otolith structures have been issued from fine-scale analysis tools [9-12], especially confocal Raman microspectrometry. This technique which is non-destructive and non-invasive, provides a qualitative and quantitative analysis of mineral and organic compounds [13-15]. This tool was intensively used for the identification of the polymorph of calcium carbonate [10] as well as for the discrimination of the calcium carbonate polymorphs (vaterite, aragonite and calcite) in different species [16-19]. More recently, owing to its micrometric spatial resolution, Raman micro-spectrometry was used to characterize otolith microstructures $[11,12]$.

However, to our knowledge, the effects of preparation methods on the quantitative characterization have not been investigated yet. Among the different steps commonly involved in the preparation of otolith thin sections, resin embedding appears as a critical one that might directly affect the elemental composition of the otoliths, as already shown for bones [20,21]. For microchemical analyses, epoxy resins such as Araldite are preferred as they are chemically inert (i.e. resin which do not contain, in detectable concentration, elements sought in the otoliths) and characterized by a low viscosity ensuring a good maintaining of the otolith during processing. Different requirements (viscosity, polymerization conditions, organic composition) should however be considered when the focus is given to organic and mineral spectral signatures.

In this study, we evaluated i) the spatial distribution and level of resin contamination in otolith thin sections and ii) the effects of resin embedding on their fine-scale mineral and organic signatures. Raman micro-spectrometry analyses were carried out to compare non-embedded samples to samples embedded with Araldite. As resin embedding does affect the otolith organic composition and thus modified the Raman spectral features of the otolith, we proposed a numerical method for contamination correction. We also discussed the extent to which previous works dedicated to the characterization of the organic and mineral fractions of the otolith including Raman micro-spectrometry analyses [11] and isotope analyses ([22] and references therein) should be revised in light of these results. 


\section{Materials and Methods}

\subsection{Otolith preparations}

We considered otoliths extracted from European hake (Merluccius merluccius, Linnaeus 1758) caught in the Northern Biscay or reared in aquaculture facilities [23] and measuring between 0.42 and $57 \mathrm{~cm}$ TL (Table 1).

Once extracted, otoliths were rinsed with MilliQ water (resistivity of $18.2 \mathrm{M} \Omega . \mathrm{cm}^{-1}$ ), dried and weighed. Only left sagittae were considered and thin sections were prepared as follows: 1 ) embedding in epoxy resin (Araldite 2020, Huntsman) 2) sectioning in transverse or sagittal plane, 3) embedding in epoxy resin on a glass slide previously covered with $1 \mathrm{~mm}$ layer of resin, 4) grinding with silicon carbide, and 5) polishing to the core with progressively finer grades of diamond suspensions ( $3 \mu \mathrm{m}, 1 \mu \mathrm{m}$ and $0.25 \mu \mathrm{m}$ grain size). Sections were ultrasonically cleaned with MilliQ water at the end of each polishing stage.

Otoliths from hake larvae extracted under polarized light and otoliths from fish measuring between 10 and $27 \mathrm{~cm}$ were also directly mounted on glass slides without any embedding. An analysis in the sagittal plane was carried out without any further preparation (Table 1).

Our investigations mainly concerned areas of interest on otoliths: i) the core area, surrounding the primordium which is the initial otolith structure, ii) checks, i.e. structural discontinuities [24] mostly located in translucent zones of hake otoliths, and iii) microstructures, each consisting of a light-zone (L-zone) and dark zone (D-zone) which deposition follows a circadian rhythm.

\subsection{Raman micro-spectrometry}

The experimental setting was the same as in Jolivet et al. [11] i.e. a micro-Raman spectrometer (Jobin-Yvon T64000) equipped with a confocal system and a motorized xystage. The Raman spectra were recorded under a microscope (Olympus BX41) in the backscattering geometry with a 100x objective (with a numerical aperture of 0.95 ) focusing the $514 \mathrm{~nm}$ line from an Argon-Krypton ion laser (Coherent, Innova) on samples with an estimated spot size of $0.8 \mu \mathrm{m}$. Raman measurements were carried out at very low laser power $(0.06 \mathrm{~mW}$ on sample) to minimize possible sample deterioration. The Raman scattered light was filtered by a holographic Super Notch filter and analyzed by a spectrometer with a single monochromator $\left(600\right.$ gratings $\mathrm{mm}^{-1}$ ) coupled to a nitrogen cooled CCD detector. Single spectra were recorded twice in the wavenumber region $100-5000 \mathrm{~cm}^{-1}$, with exposure times varying from 30 to $300 \mathrm{~s}$ depending on the sample. The depth of analysis was systematically set to $2 \mu \mathrm{m}$ below the surface to minimize possible contamination due to the preparation process.

\subsection{Analysis of organic and mineral fraction on Raman spectra}

Organic and mineral vibrational signatures were extracted from Raman spectra following the protocol previously described [11]: i) a data normalization was applied with respect to a reference acquisition setup of $50 \mathrm{~s}$ with a laser output power of $50 \mathrm{~mW}$, ii) the integrated intensities of the observed vibrational bands were extracted using the Labspec $\circledast$ software v.3.01 (Jobin-Yvon Horiba). With respect to Raman spectra of fish otoliths, the mineral fraction was characterized by 14 aragonite vibrational bands [14] and the organic fraction by 10 signatures identified on the spectra of the core, known to be a particularly organic-rich area (Table 2) [11,12]. 


\subsection{Contamination-free Raman signatures}

The position and intensity of bands on Raman spectrum relate to the chemical composition and structure of the analyzed samples. Micrometric spatial resolution of Raman spectroscopy combined with a confocal analysis makes this technique ideal for the detection of contamination agents on surfaces especially for low concentrated component analysis and chemical species inclusions. If known, the signatures of specific compounds such as resin or chemical markers (e.g. oxytetracycline used for age validation studies) can therefore, in theory, be revealed and identified in a Raman spectrum.

Araldite, as all epoxy resins, is a polymer formed from reaction between an epoxide resin (Fig. 1a, Component A) and a polyamine hardener (Fig. 1b, Component B). The Raman spectrum of Araldite (Fig. 1b) presents specific signatures at 824, 1607, 3070 and between 1200 and $1300 \mathrm{~cm}^{-1}$ (not observed in non-embedded otoliths), which were considered in the subsequent analysis to reveal and evaluate the contamination level of local otolith signatures due to resin embedding (identified by the grey area in Fig.1b).

When the recorded Raman spectra present the specific signatures of the Araldite, corrected resin-free spectra was computed as follows: we first estimated the Araldite response from the intensity of the observed band at $3070 \mathrm{~cm}^{-1}$ and then removed the contribution of Araldite spectrum from the initial recorded Raman spectrum. The resin contamination was quantified from the integrated intensity of $\mathrm{CH}$ stretching band centred at $2950 \mathrm{~cm}^{-1}\left(\mathrm{I}_{\mathrm{CH}}\right)$ measured before and after correction and expressed as a percentage of contamination ( $\mathrm{P}_{\mathrm{C}}$ in \%):

$$
\mathrm{P}_{\mathrm{C}}=\left(\mathrm{I}_{\mathrm{CH} \text {-before }}-\mathrm{I}_{\mathrm{CH} \text {-after }}\right) /\left(\mathrm{I}_{\mathrm{CH} \text {-before }}\right)
$$

Otherwise, we measured, on the corrected spectrum, the ratio between the $\mathrm{CH}$ stretching band and the strongest peak of aragonite at $1085 \mathrm{~cm}^{-1}$ as a proxy of the ratio between the organic and mineral fractions of the otolith structures.

\section{Results}

\subsection{Resin embedding contaminations}

\subsubsection{Global analysis}

Raman experiments clearly evidenced the presence of resin in otoliths even after ultrasonically cleaning. The contamination was quantitatively evaluated by the percentage of the $\mathrm{CH}$ stretching bands assigned to the resin. Indeed among the 1905 spectra obtained on prepared otoliths (i.e. including embedding step), $89 \%$ of spectra show a contamination level of otolith greater than $10 \%$.

By comparing the corrected spectra to the initial one, it was found that contamination can affect the observed spectral data with intensities variation ranging from 0 to $50 \%$ depending on the band frequency (Table 3 ). These results illustrate that the contamination is mainly restricted to few mineral and organic otolith signatures. 


\subsubsection{Core}

The comparison between the spectra obtained on the core of samples S2 and S4 and the Araldite signature depicts a strong correspondence of the organic signatures of the resin and the core of the embedded sample S2 (Fig. 2). Only the baseline and the two bands located at 1710 and $1810 \mathrm{~cm}^{-1}$ did not depict resin contamination (Fig. 2a). Several organic compounds of the otoliths core were clearly occluded by resin contamination (Fig. 2b). The Raman vibrational bands relative to Araldite and organic fraction of core on samples S2 and S4 are detailed in Table 2 with respect to those reported by Zhang et al. [12] for the core of the small yellow croaker otoliths.

The core appeared as a zone highly affected by resin embedding as the resin accounted for 80 to $100 \%$ of the Raman $\mathrm{CH}$-signature (Table 1). The spatial pattern of the Araldite contamination was characterized from a 2D-mapping of the core of sample S2 (Fig. 3: $30 \mu \mathrm{m} \times 40 \mu \mathrm{m}$ mapping with step fixed to $3 \mu \mathrm{m}$ and $2.5 \mu \mathrm{m}$ in the $X$ and $Y$ directions respectively). The highest contamination was observed on the core and much less along the anti-sulcus, dorsal and ventral directions. In contrast, the sulcus area depicted large contaminations levels (Fig. 3).

\subsubsection{Checks}

Checks depicted Raman signatures similar to those observed in the core zone. As illustrated in Fig. 4a, compared to the surrounding points, checks depicted lower aragonite signatures except for the bands at 1462 and $1571 \mathrm{~cm}^{-1}$ and greater organic compounds signatures except for the peak at $1710 \mathrm{~cm}^{-1}$ (Fig. 4a). It is worth noting that contrary to the core, the signature at $3399 \mathrm{~cm}^{-1}$ and the baseline did not vary between check and the adjacent points.

Checks also involved high contamination levels since the resin accounted for 60 to $92 \%$ the Raman $\mathrm{CH}$ stretching bands (Table 1, Fig. 4a). This contamination effect was particularly concentrated as stressed by the measure of integrated intensities of Araldite signatures along a transverse section of sample S5 (Fig. 4b).

\subsubsection{Otolith microstructures}

The effects of resin embedding were analysed on two sagittal sections embedded in Araldite (samples S8 and S9). Different levels of contamination were observed in spectra (Fig. 5a) varying from 35 to $91 \%$ for S8 and from 0 to $47 \%$ for S9. The analysis along a transect covering several L- and D-zones of sample S8 showed that L-zones were significantly more affected than D-zones (T-test, $d f=24, P<0.001$, Fig. $5 b$ ).

\subsection{Contamination correction}

\subsubsection{Core and checks}

The resin-free Raman spectra were computed for the core and check zones. Regarding the core, the correction leads to $\mathrm{CH} / \mathrm{AR}$ intensity ratios lower than the one measured on the nonembedded core (Fig. 6a).

Regarding the checks zones, the resin-free Raman spectra depicted lower variability compared to non-corrected spectra $\left(\mathrm{CH} / \mathrm{AR}_{\text {corrected }}\right.$ ranged from $0.22-0.50 \mathrm{vs}$. $\mathrm{CH} / \mathrm{AR}_{\text {contaminated }}$ ranged from 0.85 to 3.6 ). The corrected $\mathrm{CH} / \mathrm{AR}$ intensity ratio remained however significantly greater than those of otolith microstructures (T-test, $\mathrm{df}=97, \mathrm{P}<0.001$, Fig. $6 \mathrm{~b}$ ). 


\subsubsection{Otolith microstructures}

We analysed the proposed resin-free otolith Raman spectra by comparing two groups of samples. The first group comprised 20 embedded samples (Table 1, S1, S5, S8-S25, 1742 spectra) acquired in translucent and opaque zones and depicted 0 to $100 \%$ contamination levels. The second group consisted of 5 non-embedded otoliths (Table 1, S26-S30, 163 spectra). The analysis showed a lower variability of $\mathrm{CH} / \mathrm{AR}$ intensity ratios observed for contaminated samples (Fig. 7a). The corrected CH/AR intensity ratios were in the range of variations of the values issued from non-contaminated spectra (Fig. 7b). For contamination levels greater than $70 \%$ of the $\mathrm{CH}$-signatures, a non-negligible number of corrected $\mathrm{CH} / \mathrm{AR}$ intensity ratios ( $>5 \%$ of analyzed samples) are below the minimum ratio observed on noncontaminated samples (values highlighted by the gray area on Fig. 7b).

\section{Discussion}

To our knowledge, the contamination issues on otolith signatures (and more broadly the signatures of other biominerals) due to resin embedding have already been addressed and were dealt with chemically neutral resin for microchemical analyses focusing on minor or trace elements [8]. As stressed here, it may however be questioned whether or not resin embedding modified the mineral and/or organic signatures of otolith thin sections previously reported in literature $[11,12]$. Embedding is generally an exothermic reaction between both organic components (the resin and the hardener) which may affect otolith organic compounds as well as the aragonitic crystalline structure.

Contaminations due to resin embedding were here clearly evidenced from the Raman microspectrometry characterization of non-embedded and resin-embedded samples. The comparison to the reference Raman spectrum of the resin provided a quantitative evaluation of contamination levels.

\subsection{Spatial distribution and level of resin contamination in otolith thin sections}

The surface contaminations were proven spatially inhomogeneous and it may be suggested that the contaminations is correlated to the spatial distribution of the organic matrix of the otolith. Greater contamination levels were observed in the core (more than $80 \%$ ) and in structural discontinuities, such as checks (more than $60 \%$ ), known to be organic-rich structures $[25,26]$. The contamination levels of otolith microstructures depicted greater variability ranging from 0 to $100 \%$. For the six organic signatures considered, the greater levels are depicted in L-zones, as shown by Jolivet et al. [11], as well as greater contamination levels than in D-zones. For the core and the checks, it might be argued that the greater contamination levels are due to less dense crystalline structure $[11,26,27]$. This statement does not however hold for L- and D-zones, as L-zones depicted greater Raman signatures both for the organic and mineral fractions [11]. Differences in the crystalline organisation of L- and D-zones [28] might explain the differences in the observed resin embedding effects and might be confirmed by coupling Raman micro-spectrometry with a micro-scale analysis of the crystalline structure by Atomic Force Microscopy $[16,29]$ and Scanning Electron Microscope SEM.

A post-processing procedure is thus proposed to generate resin-free Raman spectra. Based on presence of specific signatures of the resin, in particular peaks between 1200 and 1300 $\mathrm{cm}^{-1}$, Raman spectra were corrected from the estimated resin contribution and the contamination level was evaluated as the relative contribution of the resin to the $\mathrm{CH}$ Raman signature. The direct validation of this procedure is not feasible as it would require analysing the same microstructures prior and after resin embedding. We thus investigated the 
comparison between the distribution of corrected $\mathrm{CH} / \mathrm{AR}$ intensity ratios of resin-embedded samples to those of non-embedded samples. It should be stressed that $\mathrm{CH} / \mathrm{AR}$ intensity ratios are highly variable across samples, microstructures ( $L-v s$. D-zones) and macrostructures (translucent vs. opaque zones). Overall, higher is the contamination level, lower is the corrected $\mathrm{CH} / \mathrm{AR}$ intensity ratios. This suggests an infiltration of the resin in the crystalline structure of the otolith and a possible modification of the characteristics of the organic matrix as a result of the exothermic polymerization of the resin. Overall, for contamination levels above $70 \%$, the Raman signatures were shown to be altered as corrected $\mathrm{CH} / \mathrm{AR}$ intensity ratios were mainly inferior to those measured on non-embedded samples.

\subsection{Consequences regarding previous interpretations of Raman otolith signatures}

Given the exhibited effects of resin embedding on the Raman signatures of organic and mineral fraction of the otoliths, one may question the conclusions drawn in previous works $[11,12,30,31]$. The samples considered in Jolivet et al. [11] were part of the current study. 89 $\%$ of these samples involved contamination levels greater than $10 \%$. However, more than 78 $\%$ of the sampled points were associated with a contamination level below $70 \%$, and, the key contributions drawn in Jolivet et al. [11] were confirmed: 1) the core is a particular point with a strong concentration in organic compounds; 2) L-zones depict stronger concentrations in mineral and organic fractions than D-zones; and 3) the relative proportion of $\mathrm{CH}$ versus AR is greater in L-zones than in D-zones. However, we cannot verify the Raman features of the checks on non-embedded samples given the systematic high level of contamination of these areas (ranged from 64 - $92 \%$ ). Checks were described as depicting lower aragonite fractions and greater organic signatures similarly to the core $[25,32,33]$. The agreement between the core and check signatures for resin-embedded sample supports this statement.

The contamination occurred at the otolith-resin interface particularly when fixing the otolith section (850 $\mu \mathrm{m}$ thickness) onto the glass slide. The section was embedded between two layers of resin, one between the otolith and the glass slide, necessary whenever the samples should be turned over to reach the core plane, and another one above the otolith. The latter was removed during grinding to obtain $100 \mu \mathrm{m}$ thickness sections for microstructure analysis, however, at the expense of a resin-embedding contamination of otolith physico-chemical signatures. This was particularly stressed for sample S8 which depicted a high contamination level. In contrast, thicker sections, such as sample, S9 with a $299 \mu \mathrm{m}$ thickness, depicted lower contamination levels. Obviously, the analysis of non-embedded samples should be preferred when possible and relevant. The preparation of otolith sections is however a prerequisite in most cases to proceed to a fine scale analysis of otolith structures. Two main guidelines may be proposed in this context: 1) resins with a rapid and endothermic polymerization should be preferred, 2) the resin layer inserted between the sample and the glass slide should be avoided whenever possible.

\subsection{Consequences for the interpretation of chemical otolith signatures}

The impact of resin embedding on the physico-chemical signatures of fish otoliths was shown here to depend on various factors: the preparation protocol, the thickness of the samples and the analyzed zones. In all cases however, one should carefully consider potential resin embedding effects in the characterization of otolith thin sections, especially when the structures of interest may depict high contamination levels, for instance the core, checks, as well as the edge of the otolith. This recommendation obviously includes studies of the organic fraction of the otolith but also the analysis of isotopic signatures of chemical elements such as carbon, oxygen and nitrogen, as well as chemical elements which bind to proteins synthesized in the endolymph, such as strontium, copper, zinc. 
The reconstruction of life history traits from carbon and oxygen isotope signatures, typically involves micromilling resin-embedded sections along transects from the core to the edge [3437]. Under this protocol, one should be cautions with drilling effects that may resort the transformation of aragonite into calcite under heating conditions [38]. To our knowledge, resin contamination effects have been widely overlooked. For instance, the core typically depicted carbon isotopic $\left(\delta^{13} \mathrm{C}\right)$ values significantly lower than the edge of the otolith, generally interpreted as a metabolism-induced signature ([22] and references therein). Our results may suggest other interpretations as the core was characterized by high contamination level (greater than $80 \%$ ) and the resin depicts low $\delta^{13} \mathrm{C}$ values (typically, $28.05 \%$ for epoxy resin, [39]). One may then question whether or not low $\delta^{13} \mathrm{C}$ values resulted from resin contamination. This hypothesis is supported by studies reported on other biominerals. In an experimental analysis of $\delta^{13} \mathrm{C}$ signatures of resin-embedded and nonembedded beluga teeth, Stewart et al. [39], have shown that the resin accounted for 5 to 30 $\%$ of the $\delta^{13} \mathrm{C}$ signature of the embedded samples. Our results strongly suggest undertaking new experiments to perform a quantitative evaluation of resin embedding effects on otolith isotopic signatures and subsequently on the reconstruction of individual life traits.

Resin contamination should also be considered with care when the focus is given to chemical elements, such as strontium or other metals, which bind to proteins of the organic matrix of the otolith. Such metal-protein interactions were reported to account for significant metal fractions in the otoliths: for instance copper and zinc in the EDTA-soluble fraction of the organic matrix of cod otoliths accounted respectively for 70 to $100 \%$ and 40 to $60 \%$ of the total mass of copper and zinc found in whole otoliths [40]. The analysis of the concentration of such chemical elements along transects on otolith sections are of great interest to reconstruct, for instance, migrations patterns from environmental variability $[2,41,42]$. They often depict high inter- and intra- individual variability. As suggested here, this variability may not only reveal environmental and metabolic conditions but also resin embedding effects on the organic matrix of the otolith and associated chemical elements. Raman micro-spectrometry appearing as a powerful non-destructive technique, these questions could be addressed by coupling this technique to a Laser Ablation Inductively Coupled Plasma Mass Spectrometry (LA-ICP-MS) analyses.

\section{References}

1. Degens ET, Deuser WG, Haedrich RL (1969) Molecular structure and composition of fish otoliths. Mar Biol 2:105-113

2. Campana SE (1999) Chemistry and composition of fish otoliths: pathways, mechanisms and applications. Mar Ecol Prog Ser 188:263-297

3. Fromentin JM, Ernande B, Fablet R, de Pontual H (2009) Importance and future of individual markers for the ecosystem approach to fisheries. Aquat Living Resour 22:395-408

4. Arslan Z, Secor DH (2008) High resolution micromill sampling for analysis of fish otoliths by ICP-MS: Effects of sampling and specimen preparation on trace element fingerprints. Mar Environ Res 66:364-371

5. Benoit G, Hunter KS, Rozan TF (1997) Sources of trace metal contamination artifacts during collection, handling, and analysis of freshwater. Anal Chem 69 (6):1006-1011

6. Proctor $\mathrm{CH}$, Thresher RE (1998) Effects of specimen handling and otolith preparation on concentration of elements in fish otoliths. Mar Biol 131:681-694

7. Rooker JR, Zdanowicz VS, Secor DH (2001) Chemistry of tuna otoliths : assessment of base composition and postmortem handling effects. Mar Biol 139:35-43

8. de Pontual H, Geffen AJ (2002) Otolith microchemistry. In: Panfili J, de Pontual H, Troadec $\mathrm{H}$, Wright PJ (eds) Manual of Fish Sclerochronology. Coedition Ifremer-IRD, Brest, France, pp 243-303 
9. Dauphin Y, Dufour E (2003) Composition and properties of the soluble organic matrix of the otolith of a marine fish: Gadus morhua Linne, 1758 (Teleostei, Gadidae). Comp Biochem Physiol A Physiol 134A:551-561

10. Gauldie RW (1999) Ultrastructure of lamellae, mineral and matrix components of fish otolith twinned aragonite crystals implications for estimating age in fish. Tissue Cell 31 (2):138-153

11. Jolivet A, Bardeau J-F, Fablet R, Paulet Y-M, de Pontual H (2008) Understanding otolith biomineralization processes: new insights into microscale spatial distribution of organic and mineral fractions from Raman micro-spectrometry. Anal Bioanal Chem 392:551-560

12. Zhang F, Cai W, Sun Z, Zhang J (2008) Regular variations in organic matrix composition of small yellow croaker (Pseudociaena polyactis) otoliths: an in situ Raman microspectrometry and mapping study. Anal Bioanal Chem 390 (2):777-782

13. Hedegaard C, Bardeau J-F, Chateigner D (2006) Molluscan shell pigments: an in situ resonance raman study. J Molluscan Stud 72 (2):157-162

14. Urmos J, Sharma SK, Mackenzie FT (1991) Characterization of some biogenic carbonates with Raman spectroscopy. Am Mineral 76 (3-4):641-646

15. Weiss IM, Tuross N, Addadi L, Weiner S (2002) Mollusc Larval Shell Formation: Amorphous Calcium Carbonate is a Precursor Phase for Aragonite. J Exp Zool 293:478-491 16. Gauldie RW, Sharma SK, Volk E (1997) Micro-Raman spectral study of vaterite and aragonite otoliths of the Coho Salmon, Oncorhynchus kisutch. Comp Biochem Physiol A Physiol 118 (3):753-757

17. Melancon S, Fryer BJ, Ludsin SA, Gagnon JE, Yang ZP (2005) Effects of crystal structure on the uptake of metals by lake trout (Salvelinus namaycush) otoliths. Can J Fish Aquat Sci 62 (11):2609-2619

18. Tomás J, Geffen AJ (2003) Morphometry and composition of aragonite and vaterite otoliths of deformed laboratory reared juvenile herring from two populations. J Fish Biol 63 (6):1383-1401

19. Tzeng WN, Chang CW, Wang CH, Shiao JC, lizuka Y, Yang YJ, You CF, Ložys L (2007) Misidentification of the migratory history of anguillid eels by $\mathrm{Sr} / \mathrm{Ca}$ ratios of vaterite otoliths. Mar Ecol Prog Ser 348:285-295

20. Mandair GS, Bateman TA, Morris MD Raman Spectroscopy of Murine Bone in Response to Simulated Spaceflight Conditions. In: Optics in bone biology and diagnostics, San Jose, CA, January 24 2009. Proceeding of SPIE, pp 716607, DOI:101117/716612.810048

21. Yeni YN, Yerramshetty J, Akkus O, Pechey C, Les CM (2006) Effect of Fixation and Embedding on Raman Spectroscopic Analysis of Bone Tissue. Calcif Tissue Int 78:363-371

22. Hidalgo M, Tomas J, Høie H, Morales-Nin B, Ninnemann US (2008) Environmental influences on the recruitment process inferred from otolith stable isotopes in Merluccius merluccius off the Balearic Islands. Aquat Biol 3 (3):195-207

23. Jolivet A, de Pontual H, Hervy M, Paulet Y-M, Fablet R (2012) Preliminary observations of survival and growth of European hake in captivity. Aquacult Res 43:949-954

24. Panfili J, de Pontual H, Troadec H, Wright PJ (2002) Manual of fish Sclerochronology. Ifremer-IRD Coeditions, Brest, France

25. Campana SE (1983) Calcium deposition and otolith check formation during periods of stress in coho salmon, Oncorhynchus kisutch. Comp Biochem Physiol A Physiol 75 (2):215220

26. Pisam M, Jammet C, Laurent D (2002) First steps of otolith formation of the zebrafish: role of glycogen? Cell Tissue Res 310 (2):163-168

27. Payan P, de Pontual H, Boeuf G, Mayer-Gostan N (2004) Endolymph chemistry and otolith growth in fish. C R Palevol 3 (6-7):535-547

28. Morales-Nin B (1987) Ultrastructure of the organic and inorganic constituents of the otoliths of the sea bass. In: Summerfeld RC, Hall GE (eds) The Age and Growth of Fish. lowa State University Press, Ames, lowa, pp 331-344

29. Dauphin Y, Dufour E (2008) Nanostructures of the aragonitic otolith of cod (Gadus morhua). Micron 39:891-896 
30. Hanson NN, Wurster CM, EIMF, Todd CD (2010) Comparison of secondary ion mass spectrometry and micromilling/continuous flow isotope ratio mass spectrometry techniques used to acquire intra-otolith $d^{18} \mathrm{O}$ values of wild Atlantic salmon (Salmo salar). Rapid commun Mass Sp 24:2491-2498

31. Zhang F, Cai W, Zhu J, Sun Z, Zhang J (2011) In Situ Raman Spectral Mapping Study on the Microscale Fibers in Blue Coral (Heliopora coerulea) Skeletons. Anal Chem 83:78707875

32. Mugiya $\mathrm{Y}$, Uchimura $\mathrm{T}$ (1989) Otolith resorption induced by anaerobic stress in the goldfish, Carassius auratus. J Fish Biol 35 (6):813-818

33. Payan P, De Pontual H, Edeyer A, Borelli G, Boeuf G, Mayer-Gostan N (2004) Effects of stress on plasma homeostasis, endolymph chemistry, and check formation during otolith growth in rainbow trout (Oncorhynchus mykiss). Can J Fish Aquat Sci 61 (7):1247-1255

34. Høie H, Andersson C, Folkvord A, Karlsen O (2004) Precision and accuracy of stable isotope signals in otoliths of pen-reared cod (Gadus morhua) when sampled with a highresolution micromill. Mar Biol 2004:1039-1049

35. Høie H, Folkvord A (2006) Estimating the timing of growth rings in Atlantic cod otoliths using stable oxygen isotopes. J Fish Biol 68 (3):826-837

36. Hufthammer AK, Høie H, Folkvord A, Geffen AJ, Andersson C, Ninnemann US (2010) Seasonality of human site occupation based on stable oxygen isotope ratios of cod otoliths. $J$ Archaeol Sci 37 (1):78-83

37. Wurster CM, Patterson WP, Cheatham MM (1999) Advances in micromilling techniques: a new apparatus for acquiring high-resolution oxygen and carbon stable isotope values and major/minor elemental ratios from accretionary carbonate. Comput Geosci 25:1159-1166

38. Foster LC, Andersson C, Høie H, Allison N, Finch AA, Johansen T (2008) Effects of micromilling on $\mathrm{d} 180$ in biogenic aragonite. G-cubed 9 (Q04013):DOI:10.1029/2007GC001911

39. Stewart REA, Campana SE, Jones CM, Stewart BE (2006) Bomb radiocarbon dating calibrates beluga (Delphinapterus leucas) age estimates. Can J Fish Aquat Sci 84:18401852

40. Miller MB, Clough AM, Batson JN, Vachet RW (2006) Transition metal binding to cod otolith proteins. J Exp Mar Biol Ecol 329:135-143

41. Secor DH, Rooker JR, Zlokovitz E, Zdanowicz VS (2001) Identification of riverine, estuarine and coastal contingents of Hudson River striped bass based upon otolith elemental fingerprints. Mar Ecol Prog Ser 211:245-253

42. Arai T, Hirata T (2006) Differences in the trace element deposition in otoliths between marine- and freshwater-resident japanese eels, Anguilla japonica, as determined by laser ablation ICPMS. Environ Biol Fish 75 (2):173-182

43. Careche M, Herrero AM, Rodriguez-Casado A, Del Mazo ML, Carmona P (1999) Structural changes of hake (Merluccius merluccius L.) fillets: effects of freezing and frozen storage. J Agric Food Chem 47 (3):952-959

44. Ikoma T, Kobayashi H, Tanaka J, Walsh D, Mann S (2003) Physical properties of type I collagen extracted from fish scales of Pagrus major and Oreochromis niloticas. Int $\mathrm{J}$ Biol Macromol 32 (3-5):199-204

45. Mary MB, Ramakrishnan V (2005) Infrared and laser Raman spectral studies of bis(DLaspartic acid) sulfate. Spectrochim Acta A: Mol Biomol Spectrosc 62 (1-3):164-170

46. Piot O, Autran J-C, Manfait M (2000) Spatial distribution of protein and phenolic constituents in wheat grain as probed by confocal Raman microspectroscopy. J Cereal Sci $32(1): 57-71$

47. Karayannidou EG, Achilias DS, Sideridou ID (2006) Cure kinetics of epoxy-amine resins used in the restoration of works of art from glass or ceramic. Eur Polymer J 42 (12):33113323 
Table 1: Otoliths (sagittae) analyzed by Raman micro-spectrometry to evaluate resin embedding effects on vibrational spectra: fish origin, size (total length TL in $\mathrm{cm}$ ), thickness of otolith sections (in $\mu \mathrm{m}$ ), type of otolith section, preparation method with or without resin embedding, mean resin contamination measured on $\mathrm{CH}$-signatures (in \%, see text) calculated on all spectra of each sample and number $(\mathrm{N})$ of spectra acquired on each otolith. ND: Non detectable.

\begin{tabular}{|c|c|c|c|c|c|c|c|}
\hline Name & Origin & $T L$ & Thickness & Section & $\begin{array}{c}\text { Resin } \\
\text { embedding }\end{array}$ & Contamination & $N$ \\
\hline \multicolumn{8}{|c|}{ Analyse of Core } \\
\hline $\mathrm{S} 1$ & Reared & 25 & 150 & Transversal & Yes & 100 & 1 \\
\hline S2 & Wild & 33 & 394 & Transversal & Yes & 90 & 1 \\
\hline S3 & Wild & 20 & 325 & Transversal & Yes & 84 & 1 \\
\hline S4 & Reared & 0.42 & & Sagittal & No & ND & 1 \\
\hline \multicolumn{8}{|c|}{ Analyse of Check } \\
\hline S5 & Wild & 36 & 120 & Transversal & Yes & $80 \pm 4$ & 2 \\
\hline S6 & Reared & 50 & 248 & Transversal & Yes & $83 \pm 12.5$ & 2 \\
\hline $\mathrm{S} 7$ & Reared & 57 & 243 & Transversal & Yes & $74 \pm 8$ & 2 \\
\hline \multicolumn{8}{|c|}{$\begin{array}{l}\text { Analyse } \\
\text { microstructures }\end{array}$} \\
\hline s1 & Reared & 25 & 150 & Transversal & Yes & $13 \pm 14$ & 10 \\
\hline S5 & Wild & 36 & 120 & Transversal & Yes & $16 \pm 10$ & 138 \\
\hline S8 & Wild & 21 & 90 & Sagittal & Yes & $65 \pm 12$ & 64 \\
\hline s9 & Wild & 34 & 299 & Sagittal & Yes & $36 \pm 21$ & 171 \\
\hline S10 & Reared & 40 & 210 & Transversal & Yes & $83 \pm 21$ & 9 \\
\hline $\mathrm{S} 11$ & Wild & 28 & 210 & Transversal & Yes & $26 \pm 12$ & 347 \\
\hline $\mathrm{S} 12$ & Wild & 35 & 90 & Transversal & Yes & $50 \pm 14$ & 251 \\
\hline S13 & Wild & 42 & 162 & Transversal & Yes & $43 \pm 20$ & 405 \\
\hline S14 & Wild & 40 & 204 & Transversal & Yes & $35 \pm 16$ & 92 \\
\hline S15 & Wild & 30 & 221 & Transversal & Yes & $10 \pm 6$ & 6 \\
\hline S16 & Wild & 33 & 418 & Sagittal & Yes & $57 \pm 14$ & 20 \\
\hline S17 & Wild & 23 & 172 & Transversal & Yes & $26 \pm 16$ & 22 \\
\hline S18 & Wild & 26 & 102 & Transversal & Yes & $38 \pm 10$ & 13 \\
\hline S19 & Wild & 42 & 216 & Transversal & Yes & $2 \pm 5$ & 40 \\
\hline S20 & Wild & 20 & 116 & Transversal & Yes & $3 \pm 5$ & 4 \\
\hline S21 & Wild & 21 & 256 & Transversal & Yes & $9 \pm 8$ & 2 \\
\hline S22 & Wild & 30 & 136 & Transversal & Yes & $2 \pm 6$ & 10 \\
\hline S23 & Wild & 20 & 111 & Transversal & Yes & $7 \pm 8$ & 8 \\
\hline S24 & Wild & 22 & 110 & Transversal & Yes & $3 \pm 6$ & 76 \\
\hline S25 & Wild & 20 & 475 & Transversal & Yes & $51 \pm 14$ & 54 \\
\hline S26 & Wild & 26 & & Sagittal & No & ND & 3 \\
\hline S27 & Wild & 27 & & Sagittal & No & ND & 3 \\
\hline S28 & Wild & 22 & & Sagittal & No & ND & 4 \\
\hline S29 & Wild & 21 & & Sagittal & No & ND & 3 \\
\hline $\mathrm{S} 30$ & Wild & 10.5 & & Sagittal & No & ND & 150 \\
\hline
\end{tabular}


Table 2: Raman shifts and assignments of the Raman vibrational bands corresponding to the organic fraction of the core of sample S4 (resin-free sample), sample S2 (embedded sample) and Araldite. They are compared to the results reported by Zhang et al. [12] on small yellow croaker otoliths.

\begin{tabular}{|c|c|c|c|c|}
\hline \multicolumn{4}{|c|}{ Raman shifts $\left(\mathrm{cm}^{-1}\right)$} & \multirow{2}{*}{ Band attribution [12,43-46] } \\
\hline Zhang [12] & Sample S4 & Sample S2 & Araldite & \\
\hline 765 & 771 & 771 & 771 & Trp, amide IV, V \\
\hline 830 & & 824 & 824 & v-ring, Tyr, Ac Asp \\
\hline 853 & 856 & 856 & & $\delta(\mathrm{CCH})$ ring, Trp, Val, Hyp,Tyr \\
\hline \multirow[t]{4}{*}{880} & 870 & 870 & & $\delta(C C)$ ring, Trp, Val, Hyp \\
\hline & & 894 & 894 & $\mathrm{v}(\mathrm{C}-\mathrm{C})$ \\
\hline & & 916 & 916 & $\mathrm{v}(\mathrm{C}-\mathrm{C})$ of Pro ring \\
\hline & & 936 & 936 & $\mathrm{v}(\mathrm{C}-\mathrm{C})$ of protein backbone \\
\hline 940 & 950 & 950 & & Nonaromatic v(C-C), Lys, Val, Leu \\
\hline 1003 & 1005 & & & $\mathrm{C}-\mathrm{C}$ aromatic ring stretching, Phe \\
\hline \multirow[t]{4}{*}{1031} & 1031 & & & $v(C-C)$ aromatic rings, Phe, Pro, Tyr, Thr \\
\hline & & 1185 & 1185 & Tyr \\
\hline & & 1229 & 1229 & Amide III \\
\hline & & 1254 & 1254 & $\mathrm{~d}\left(\mathrm{NH}_{2}\right)$, amide III \\
\hline 1272 & 1275 & 1275 & & $\mathrm{~d}\left(\mathrm{NH}_{2}\right)$, Amide III \\
\hline \multirow[t]{3}{*}{1297} & 1297 & 1297 & 1297 & $\delta(\mathrm{C}=\mathrm{H})$, phospholipids \\
\hline & 1377 & 1377 & & $\mathrm{CH}_{2}$ wag \\
\hline & & 1387 & 1387 & $\mathrm{CH}_{2}$ wag \\
\hline 1443 & 1440 & 1444 & & $\mathrm{CH}_{2}, \mathrm{CH}, \mathrm{CH}_{3}$ bending \\
\hline 1461 & 1461 & 1461 & 1457 & $\mathrm{CH}_{2}$ wag, Aragonite \\
\hline \multirow[t]{3}{*}{1555} & & & & $\mathrm{v}(\mathrm{C}=\mathrm{C}), \operatorname{Trp}$ \\
\hline & & 1581 & 1581 & Trp v-ring, Pro, Hyp \\
\hline & 1605 & 1610 & 1610 & Trp, Phe, Tyr v-ring \\
\hline \multirow[t]{2}{*}{1660} & 1665 & 1665 & & $\mathrm{v}(\mathrm{C}=\mathrm{O})$ Amide \\
\hline & 1710 & 1710 & & V(c=u)Amide 1 \\
\hline \multirow[t]{2}{*}{2852} & 2855 & & & $\mathrm{v}\left(\mathrm{CH}_{2}\right) \mathrm{svm}$ linids \\
\hline & & 2873 & 2873 & 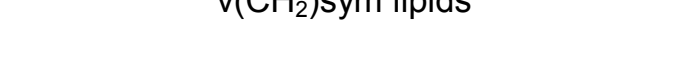 \\
\hline \multirow[t]{2}{*}{2882} & 2888 & & & $\mathrm{v}\left(\mathrm{CH}_{2}\right)$ asym lipids, $\mathrm{v}\left(\mathrm{CH}_{2}\right)$ sym proteins \\
\hline & & 2925 & 2925 & $\mathrm{v}\left(\mathrm{CH}_{3}\right)$ sym proteins and lipids, $\mathrm{v}\left(\mathrm{CH}_{2}\right)$ asym \\
\hline \multirow[t]{3}{*}{2942} & 2939 & & & proteins \\
\hline & & 3070 & 3070 & $\mathrm{CH}$ stretch \\
\hline & 3082 & & & \\
\hline
\end{tabular}


Table 3: Intensity variations (in \%) observed for the different aragonite (AR) and organic (OM) signatures on Raman spectra for a contamination level of $50 \%$.

\begin{tabular}{ccc}
\hline Raman shifts range $\left(\mathrm{cm}^{-}\right.$ & Intensity variation \\
1) & Assignements & $\begin{array}{c}\text { (\%) } \\
\text { Group 150 }\end{array}$ \\
Group 700 & AR & 0 \\
855 & OM & 0 \\
1085 & AR & 31.2 \\
1461 & AR / OM & 0.6 \\
1571 & AR / OM & 13.4 \\
Group 1700 & OM & 4.6 \\
2950 & OM & 0 \\
3399 & OM & 50 \\
& & 2.6 \\
\hline
\end{tabular}




\section{Figures}

Fig. 1: a) Molecular structure of the epoxy resin Araldite 2020 with its two compounds: the resin and the hardener (reported in [47]), b) Raman spectra of the Araldite 2020 with in bold the peak positions used to detect the contamination and in the grey area, the Raman shift zone $\left(\mathrm{cm}^{-1}\right)$ used to analyze the spatial distribution of the contamination.

a)

Component A: Diglycidyl ether of bisphenol A - DGEBA (epoxy prepolymer resin)<smiles>CC(CC(O)COc1ccc(C(C)(C)c2ccc(OCC3CO3)cc2)cc1)c1ccc(OCC(C)(C)c2ccc(OCC3CO3)cc2)cc1</smiles>

Diglycidyl ether of 1,4 butanediol - DGEBOH

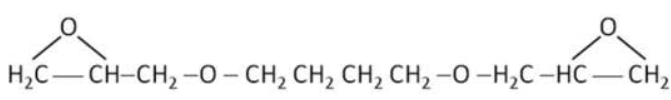

Component B: Isophorone diamine - IPDA (Hardener)<smiles>CC1(C)CC(N)CC(C)(CN)C1</smiles>

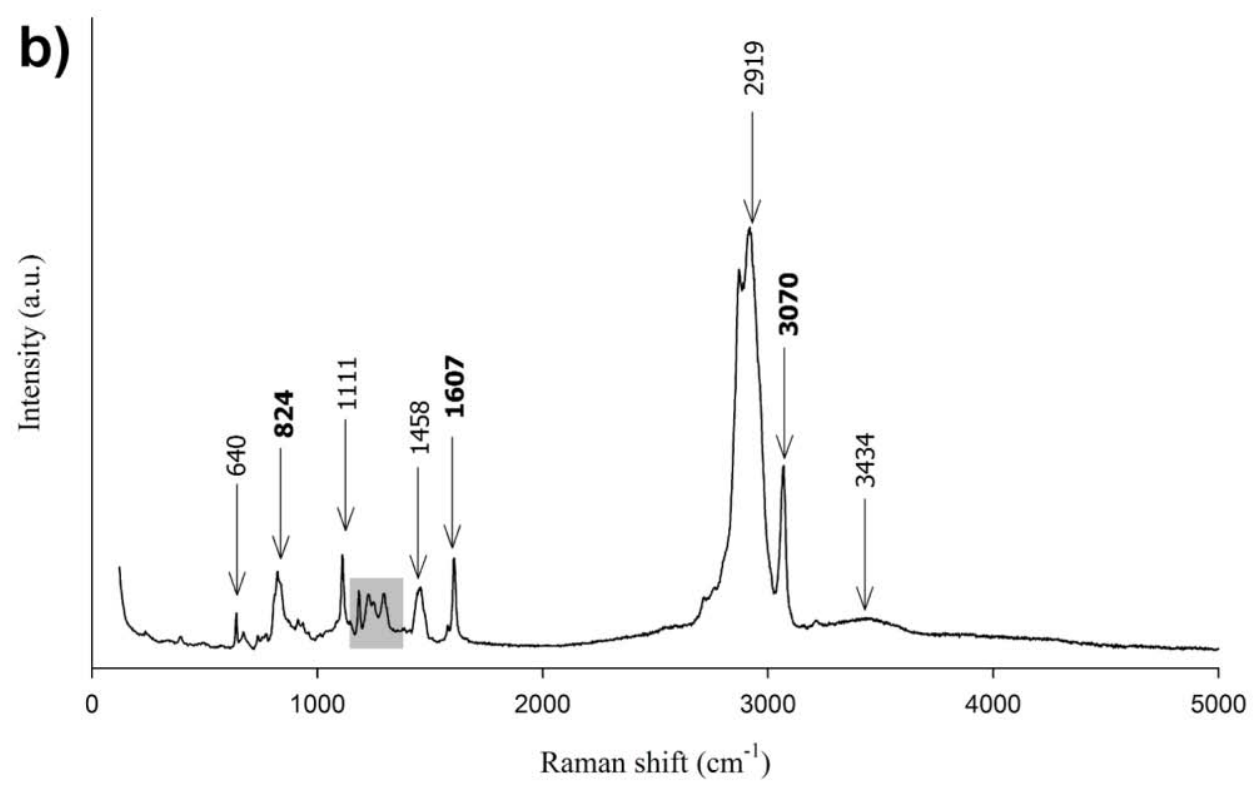


Fig. 2: (a) Comparison between the spectra acquired on the core of sample S2 (contaminated), sample S4 (non-embedded) and the Araldite signature; with (b) a focus on the $700-1900 \mathrm{~cm}^{-1}$ region. Peaks indicated in bold correspond to region non-impacted by the resin contamination. The other pointed peaks correspond to the organic signatures relative to the otolith composition and masked by the resin contamination.
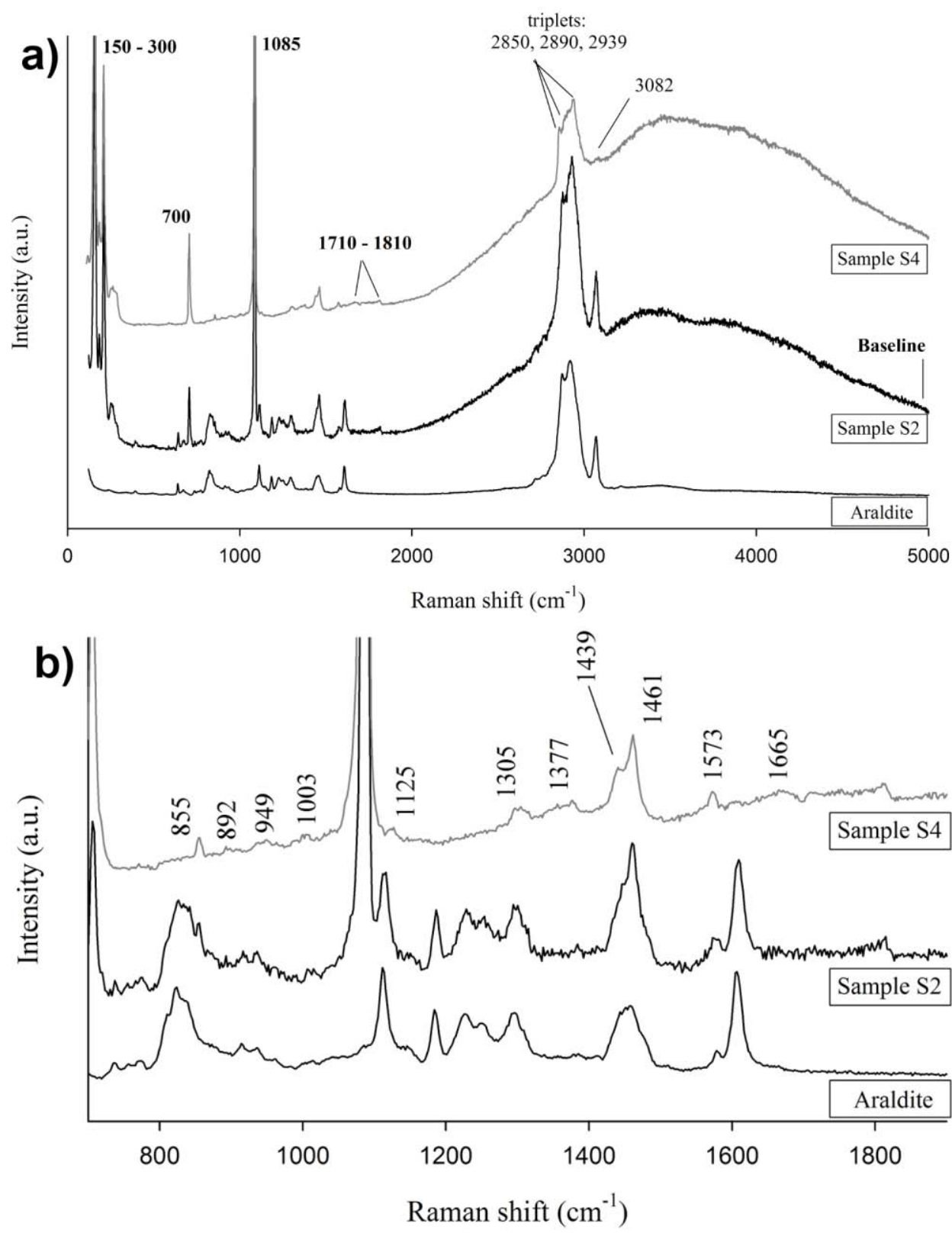
Fig. 3: Superposition of the view of $S 2$ thin section under light microscopy (scale bar: $5 \mu \mathrm{m}$ ) and the 2D-mapping (30 $\mu \mathrm{m} \times 40 \mu \mathrm{m})$ centred on the core with step increments fixed to $3 \mu \mathrm{m}$ and $2.5 \mu \mathrm{m}$ in the $X$ and $Y$ directions respectively. The mapping shows the distribution of the percentage of Araldite contamination (D: Dorsal, V: Ventral, S: Sulcus, AS: Anti-sulcus, C: Core).

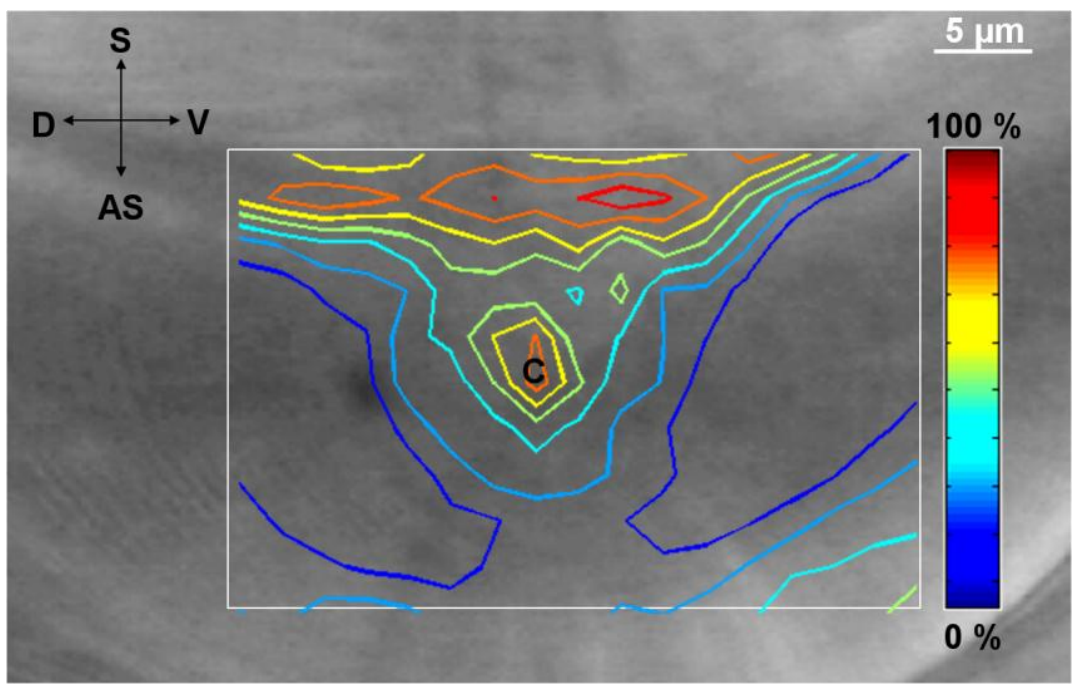


Fig. 4: Analysis of a transverse section of sample S5 presenting a check: a) Comparison of Raman spectra in the 100-5000 $\mathrm{cm}^{-1}$ region for check (in black) and the average of the five adjacent points acquired every $1.2 \mu \mathrm{m}$ on both sides of the check (in grey). The spectra thickness of the grey line corresponds to the standard deviation measured on the adjacent points. Pointed peaks correspond to region non-impacted by the resin contamination. b) Distribution of the contamination determined from the integrated intensities of the bands characteristics of the Araldite resin located between 1100 and $1300 \mathrm{~cm}-1$ characteristics of the Araldite resin.

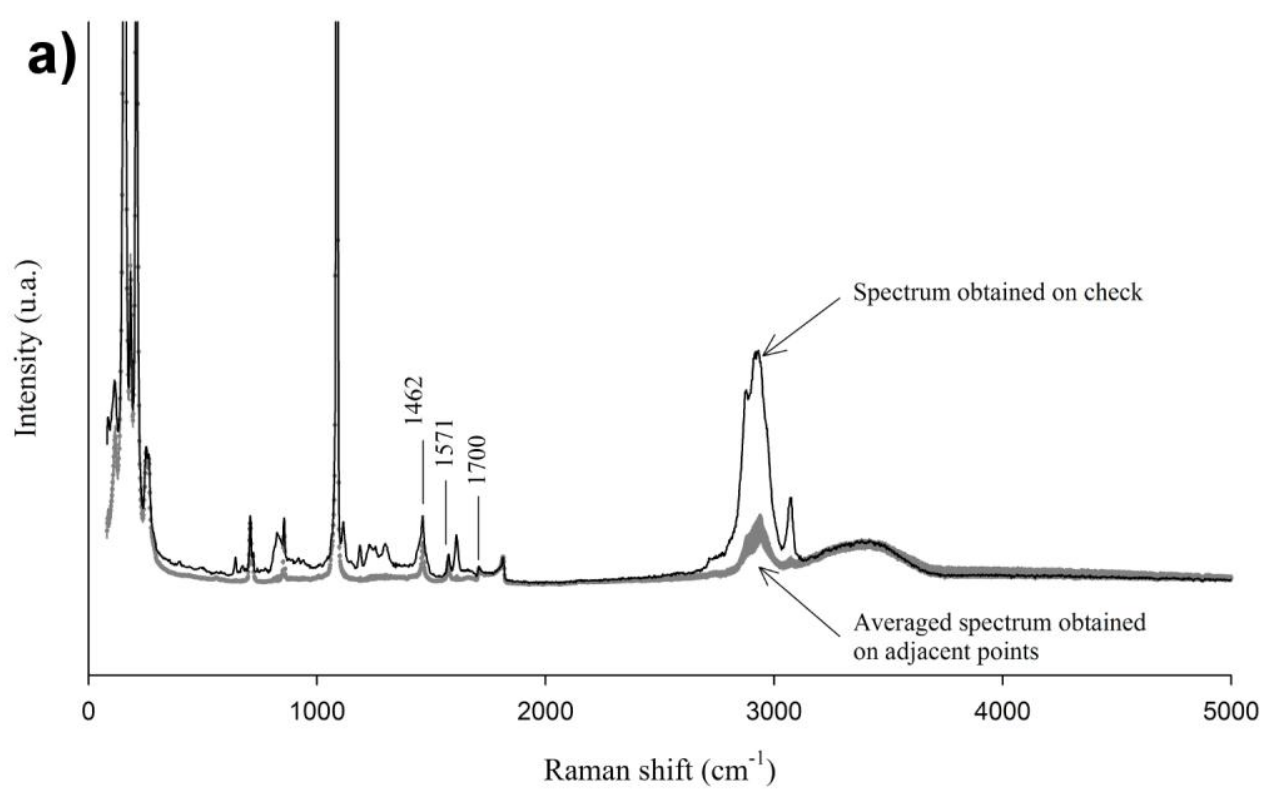

b)

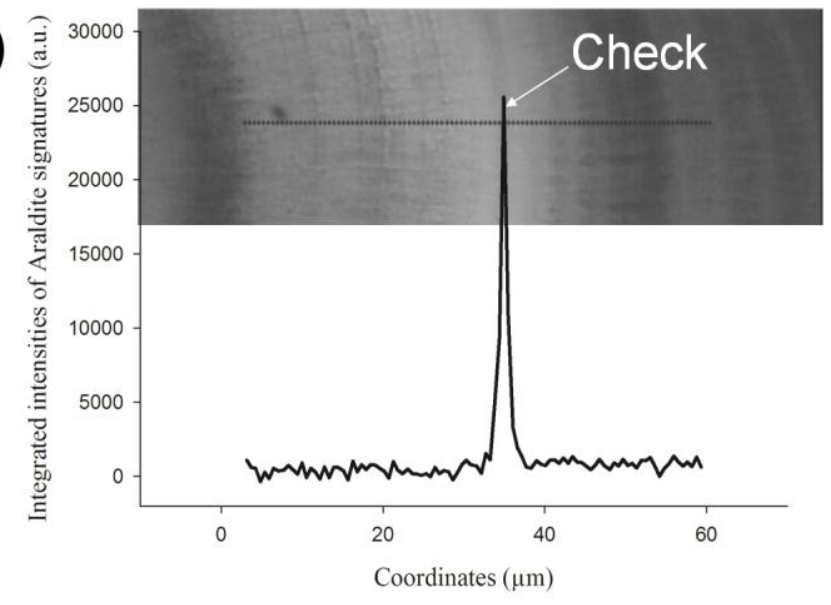


Fig. 5: a) Comparison between Araldite spectrum and Raman spectra obtained on L-zones (grey) and D-zones (dark) of sample S8 (highly contaminated) and S9 (less contaminated). Specific bands corresponding to araldite contamination are marked by grey areas. b) Distribution of the contamination calculated from the Raman integrated intensities of the bands located between 1100 and $1300 \mathrm{~cm}^{-1}$ along a transect on S8 covering successive Land D-zones. D-zones (D) are marked by grey areas.
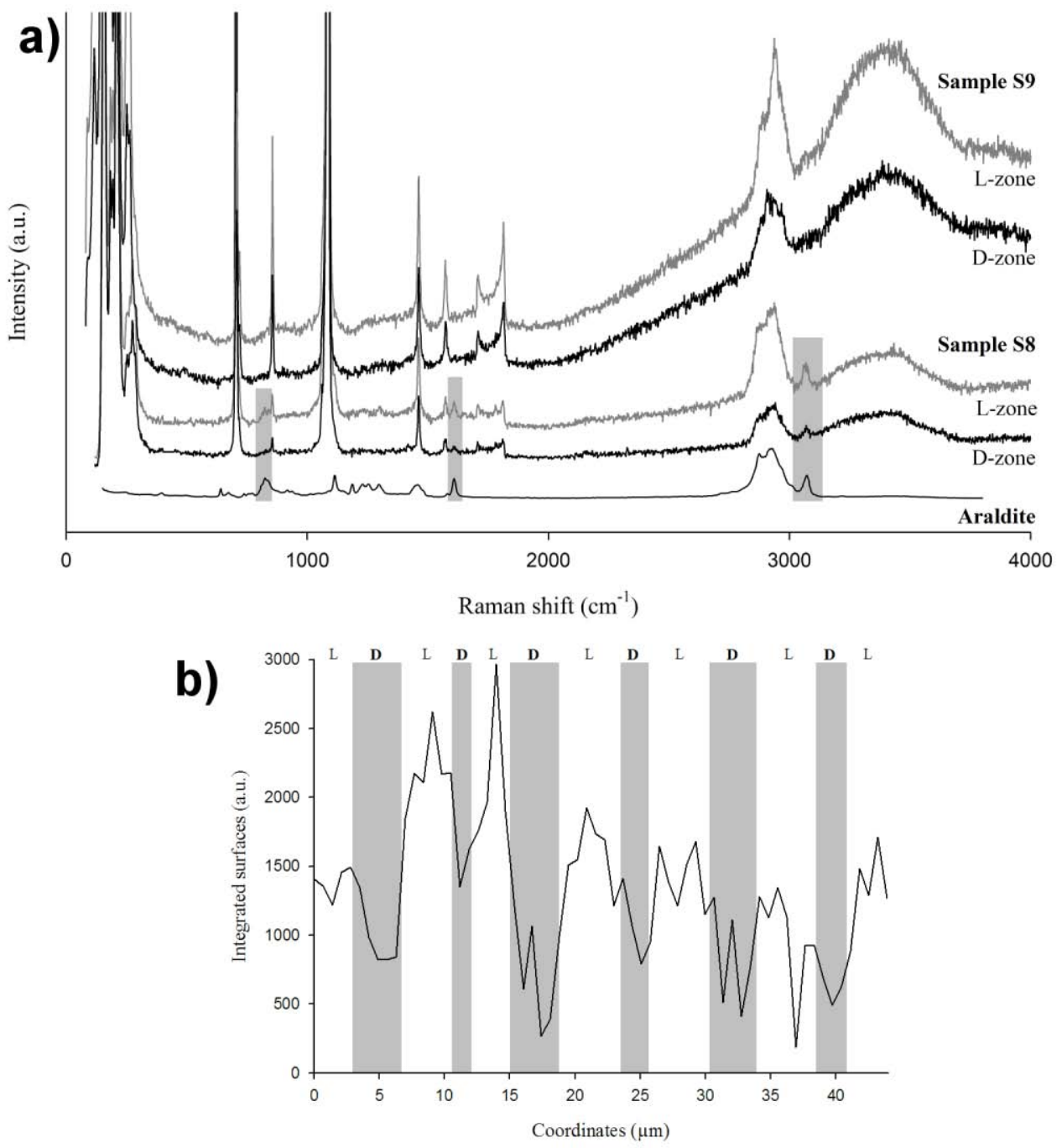
Fig. 6: Evaluation of the contamination effect on the intensity ratio between $\mathrm{CH}$-signature (at $2950 \mathrm{~cm}^{-1}$ ) and the aragonite reference $\left(\right.$ at $1085 \mathrm{~cm}^{-1}$ ) for the core a) and the check b) zones By comparison between contaminated data, corrected data and non-contaminated data. Numbers correspond to the percentage of contamination.
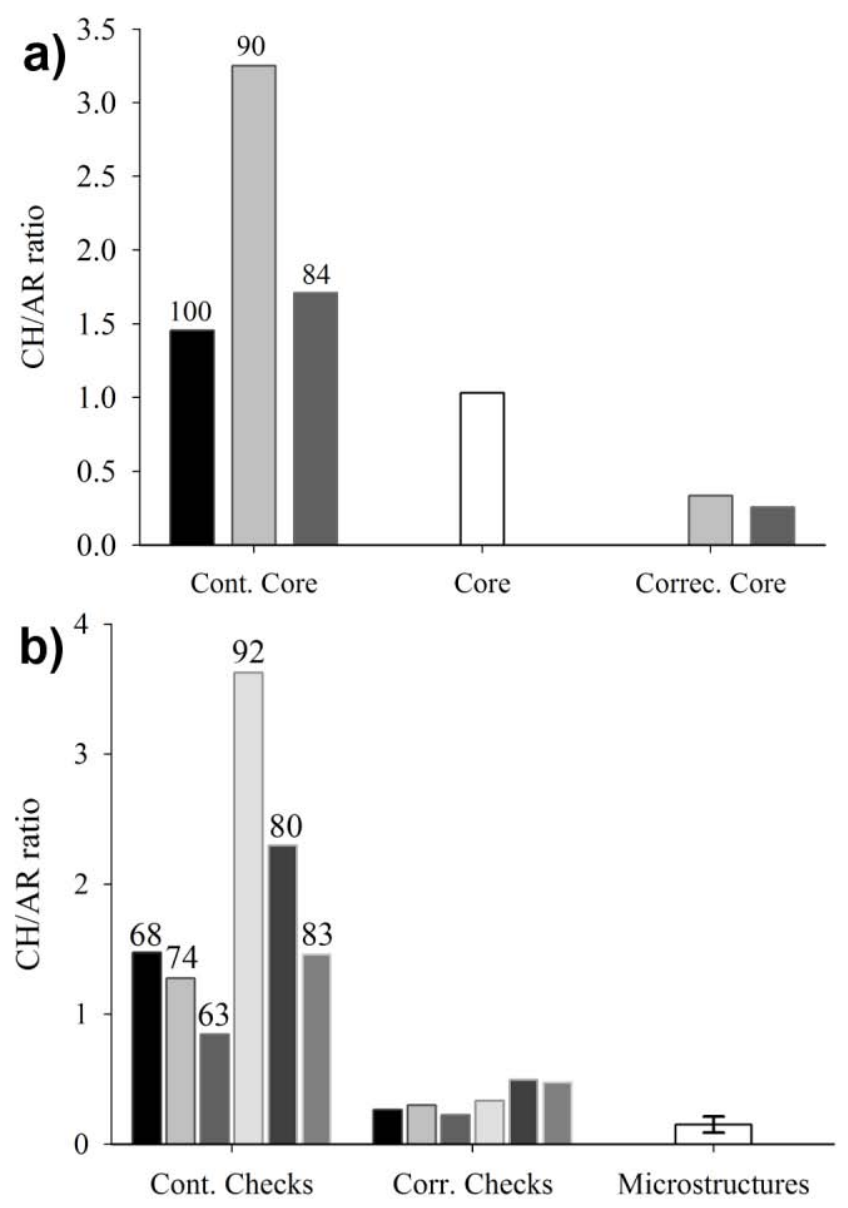
Fig. 7: Distribution of contaminated a) and corrected b) values of $\mathrm{CH} / \mathrm{AR}$ intensity ratio with respect to the percentage of contamination measured from $\mathrm{CH}$-signatures acquired on microstructures. A box plot representation was used with: the boundary for the $25^{\text {th }}$ and $75^{\text {th }}$ percentiles, the line within the box for the median, the whiskers (error bars) above and below the box for the $90^{\text {th }}$ and $10^{\text {th }}$ percentiles and the black points for the $5^{\text {th }}$ and $95^{\text {th }}$ percentiles. Corrected $\mathrm{CH} / \mathrm{AR}$ intensity ratios inferior to the minimum ratio observed on non-contaminated samples (horizontal grey line) are marked in the grey area.
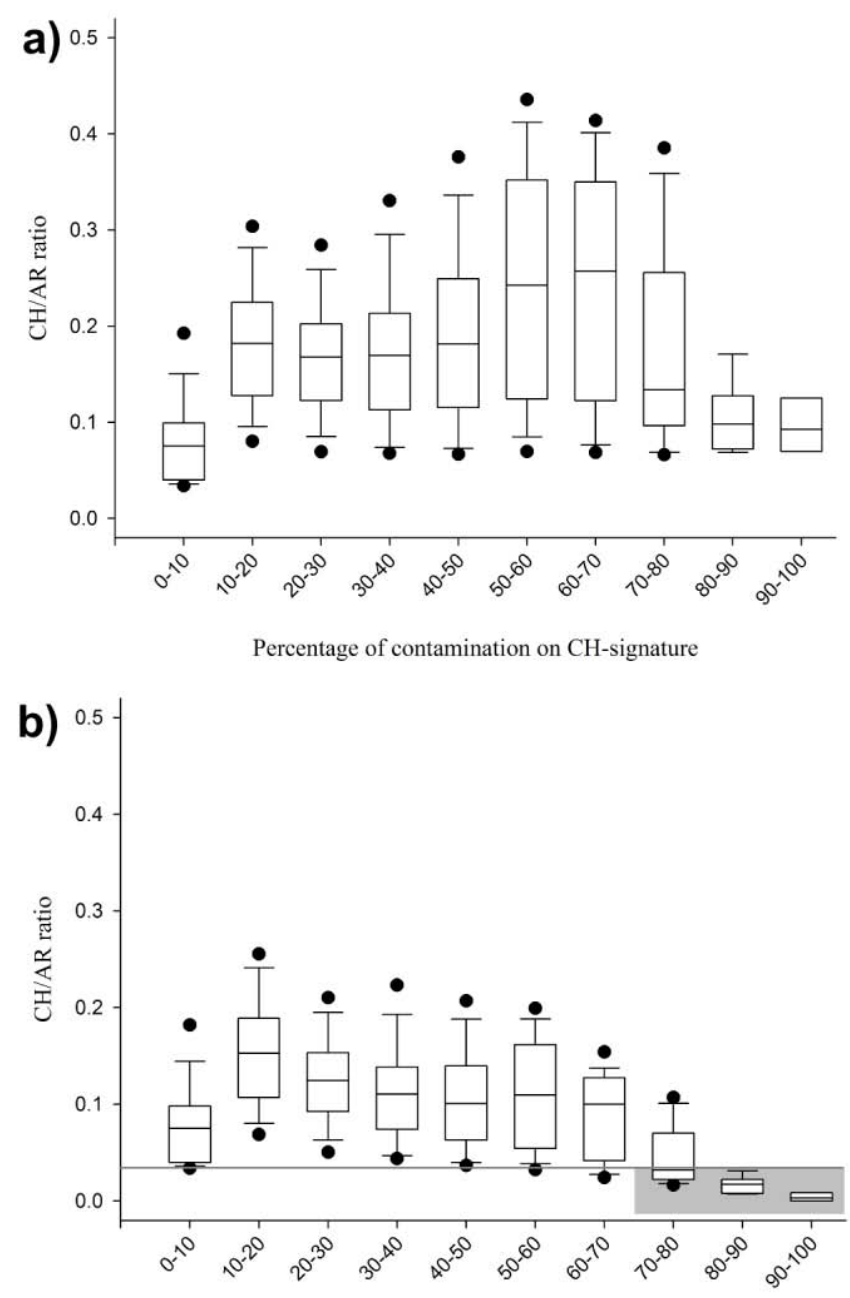

Percentage of contamination on $\mathrm{CH}$-signature 